\title{
Varl-SIG 2015: methods for personalized medicine - the role of variant interpretation in research and diagnostics
}

\author{
Yana Bromberg ${ }^{1,2^{*}}$, Emidio Capriotti $3^{3^{*}}$ and Hannah Carter ${ }^{4^{*}}$
}

From Varl-SIG at ISMB 2015

Dublin, Ireland. 07 November 2015

\section{Introduction}

The growing availability of high-throughput sequencing continues to increase the number of identified genetic variants $[1,2]$. For example, the size of the dbSNP database [3] has grown exponentially over the past years to $\sim 150$ million human single nucleotide polymorphisms and short genomic variants. Unfortunately, the characterization, annotation, and interpretation of these variants are still lagging. In particular, their implication in disease is one of the major challenges in personalized medicine [4-8].

The 5th edition of the Variant Interpretation Special Interest Group (VarI-SIG, formerly SNP-SIG) meeting [9-12] was held on July 11th, 2015 at the joint ISMB/ ECCB meeting in Dublin, Ireland. The central VarI-SIG themes were "Annotation and prediction of structural/ functional impacts of coding variants" and "Genetic variants as effectors of change: disease and evolution". Our meeting is organized as a venue for the development of a research network of scientists, necessary for facilitating the exchange of ideas and establishing new collaborations. This year's meeting attracted over 60 participants, with eight research talks and five presentations from the leading scientists in the field.

\footnotetext{
*Correspondence: yanab@rci.rutgers.edu; emidio.capriotti@hhu.de; hkcarter@ ucsd.edu

'Department of Biochemistry and Microbiology, Rutgers University, Lipman Hall 218, 08901 New Brunswick, NJ, USA

${ }^{3}$ Institute for Mathematical Modeling of Biological Systems, Department of Biology, Heinrich Heine University Düsseldorf, Universitaetsstr. 1, 40225 Düsseldorf, Germany

${ }^{4}$ Division of Medical Genetics, Department of Medicine, University of California, San Diego, 9500 Gilman Dr., 92093 La Jolla, CA, USA

Full list of author information is available at the end of the article
}

\section{Manuscript submission and review}

For this year's VarI-SIG special issue we received eight manuscript submissions. All manuscripts were evaluated by at least two reviewers, selecting from a panel of three editors and 17 other experts in the field (see Acknowledgements). After 2 rounds of review seven manuscripts were accepted for publication. These address a description of a phenotype-dependent variant/ gene prioritization method [13], annotation of variants specifically in protein kinases [14] and, generically, in regulatory regions [15], analysis of genetic variants associated with Alzheimer's Disease [16], identification of the role of protein stability OMIM disease-related variants [17], and the study of mutation profiles in cancer genomes $[18,19]$.

[The complete program of VarI-SIG meeting 2015 with presentation and poster abstracts is available at http://varisig.biofold.org/2015/docs/vari-sig-2015-prog ramme.pdf]

\section{Further developments}

We are working to organize the next VarI-SIG meeting (ISMB 2016; Orlando, Florida; July 9th, 2016). Further information about this coming meeting is available on our website (http://varisig.biofold.org).

Last year, in collaboration with the ISMB organizers, we introduced VarI-COSI (Variant Interpretation Community of Special Interest). VarI-COSI is a community aimed at sharing relevant information, discussing ideas, and providing training and support networks in the field of genomic interpretation. The web portal for VarI-COSI is under development and is accessible via ISCB Connect (http://connect.iscb.org/home). We welcome input and participation from the variation interpretation community. 


\section{Acknowledgments}

We thank Frank Schacherer and BIOBASE International for their financial support. We acknowledge Rachael Sykes and the editorial staff of BioMed Central for their help with releasing this issue. We would like to extend special thanks for all help to the ISMB organizational committee and specifically Steven Leard and Jeremy Hennig.

We also thank the invited speakers: Søren Brunak (University of Copenhagen, Copenhagen, Denmark), Anna Goldenberg (University of Toronto, Toronto, ON), Nuria Lopez-Bigas (University Pompeu Fabra, Barcelona, Spain), Yves Moreau (KU Leuven, Leuven, Belgium) and Joris Veltman (Radboud University, Nijmegen, Netherlands).

Finally, we are very grateful for the patience and help of our colleagues around the world who reviewed the submitted manuscripts. The Varl-SIG 2015 special issue would has not be possible without them: Domenico Cozzetto (University College London, London UK), Xavier de la Cruz (Vall d'Hebron Institute of Research, Barcelona, Spain), Yves Dehouck, (Université Libre de Bruxelles, Bruxelles, Belgium), Florian Gnad (Genentech, San Francisco, USA), Liang-Tsung Huang (Mingdao University, Changhua, Taiwan), Jae-Yoon Jung (Stanford University, Palo Alto, USA), Soo Heon Kwak (Seoul National University Hospital, Seoul South Korea), Polona Le Quesne Stabej (University College London, London, UK), Anthony Mathelier (University of British Columbia, Vancouver, Canada), Bo Peng (MD Anderson Cancer Center, Houston, USA), David Tamborero (University Pompeu Fabra, Barcelona, Spain), Ali Torkenami (Scripps Institute, San Diego, USA), Hua Wang (Colorado School of Mines, Golden, USA), Federico Zambelli (University of Milan, Milan Italy) and other anonymous reviewers.

\section{Declarations}

This supplement has not been supported by sponsorship. This article has been published as part of BMC Genomics Volume 17 Supplement 2, 2016: Proceedings. of Varl-SIG 2015: Identification and annotation of genetic variants in the context of structure, function, and disease. The full contents of the supplement are available online at https://bmcgenomics.biomedcentral.com/articles/supplements/volume17-supplement-2.

\section{Availability of data and material}

No data are associated to this manuscript.

\section{Authors' contributions}

$\mathrm{YB}, \mathrm{EC}$ and $\mathrm{HC}$ wrote the manuscript. All the authors read and approved the manuscript.

\section{Competing interests}

The authors declare they have no conflict of interests in relation to this VarlSIG 2015 special issue article.

\section{Author details}

'Department of Biochemistry and Microbiology, Rutgers University, Lipman Hall 218, 08901 New Brunswick, NJ, USA. 'Department of Genetics, Rutgers University, Lipman Hall 218, 08901 New Brunswick, NJ, USA. ${ }^{3}$ Institute for Mathematical Modeling of Biological Systems, Department of Biology, Heinrich Heine University Düsseldorf, Universitaetsstr. 1, 40225 Düsseldorf, Germany. ${ }^{4}$ Division of Medical Genetics, Department of Medicine, University of California, San Diego, 9500 Gilman Dr., 92093 La Jolla, CA, USA.

\section{Published: 23 June 2016}

\section{References}

1. Capriotti E, Nehrt NL, Kann MG, Bromberg Y. Bioinformatics for personal genome interpretation. Brief Bioinform. 2012;13(4):495-512.

2. 1000 Genomes Project Consortium, Abecasis GR, Auton A, Brooks LD, DePristo MA, Durbin RM, Handsaker RE, Kang HM, Marth GT, McVean GA. An integrated map of genetic variation from 1,092 human genomes. Nature. 2012;491(7422):56-65.

3. Sherry ST, Ward MH, Kholodov M, Baker J, Phan L, Smigielski EM, Sirotkin K. dbSNP: the NCBI database of genetic variation. Nucleic Acids Res. 2001;29(1):308-11.

4. Fernald GH, Capriotti E, Daneshjou R, Karczewski KJ, Altman RB. Bioinformatics challenges for personalized medicine. Bioinformatics. 2011;27(13):1741-8.
5. MacArthur DG, Manolio TA, Dimmock DP, Rehm HL, Shendure J, Abecasis GR, Adams DR, Altman RB, Antonarakis SE, Ashley EA et al. Guidelines for investigating causality of sequence variants in human disease. Nature. 2014;508(7497):469-76.

6. Bromberg Y. Building a genome analysis pipeline to predict disease risk and prevent disease. J Mol Biol. 2013;425(21):3993-4005.

7. Niroula A, Vihinen M. Variation interpretation predictors: principles, types, performance and choice. Hum Mutat. 2016;37(6):579-97.

8. Tian R, Basu MK, Capriotti E. Computational methods and resources for the interpretation of genomic variants in cancer. BMC Genomics. 2015;16 Suppl 8:S7.

9. Bromberg Y, Capriotti E. SNP-SIG Meeting 2011: identification and annotation of SNPs in the context of structure, function, and disease. BMC Genomics. 2012;13 Suppl 4:S1.

10. Bromberg Y, Capriotti E. Thoughts from SNP-SIG 2012: future challenges in the annotation of genetic variations. BMC Genomics. 2013;14 Suppl 3:S1.

11. Bromberg Y, Capriotti E. SNP-SIG 2013: from coding to non-coding-new approaches for genomic variant interpretation. BMC Genomics. 2014;15 Suppl 4:S1.

12. Bromberg Y, Capriotti E. Varl-SIG 2014-From SNPs to variants: interpreting different types of genetic variants. BMC Genomics. 2015;16 Suppl 8:11.

13. Stelzer G, Plaschkes I, Oz-Levi D, Alkelai A, Olender T, Zimmerman S, Twik M, Belinky F, Fishilevich S, Nudel R, Guan-Golan Y, Warshawsky D, Dahary D, Kohn A, Mazor Y, Kaplan S, Iny Stein T, Baris HN, Rappaport N, Safran M Lancet D. VarElect: the phenotype-based variation prioritizer of the GeneCards Suite. BMC Genomics 2016;17(Suppl 2):S1.

14. Pons T, Vazquez M, Matey-Hernandez ML, Brunak S, Valencia A, Izarzugaza JM. KinMutRF: A random forest classifier of sequence variants in the human protein kinase superfamily. BMC Genomics. 2016;17(Suppl 2):S2.

15. Kaplun A, Krull M, Lakshman K, Matys V, Lewicki B, Hogan JD. Establishing and validating regulatory regions for variant annotation and expression analysis. BMC Genomics. 2016;17(Suppl 2):S3.

16. Ayers KL, Mirshahi UL, Wardeh AH, Murray MF, Hao K, Glicksberg BS, Li S, Carey DJ, Chen R. A loss of function variant in CASP7 protects against Alzheimer's disease in homozygous APOE $\varepsilon 4$ allele carriers;17 Suppl 2:S4.

17. Martelli PL, Fariselli P, Savojardo C, Babbi G, Aggazio F, Casadio R. Large scale analysis of protein stability in OMIM disease related human protein variants. BMC Genomics. 2016;17(Suppl 2):S5.

18. Tenghui Chen T, Wang Z, Zhou W, Chong Z, Meric-Bernstam F, Mills GB, Chen $\mathrm{K}$. Hotspot mutations delineating diverse mutational signatures and biological utilities across cancer types. BMC Genomics. 2016;17(Suppl 2):S6.

19. Vorontsov IE1 Khimulya G, Lukianova EN, Nikolaeva DD, Eliseeva IA, Kulakovskiy IV, Makeev VJ. Negative selection maintains transcription factor binding motifs in human cancer. BMC Genomics. 2016;17(Suppl 2):S7.

\section{Submit your next manuscript to BioMed Central and we will help you at every step:}

- We accept pre-submission inquiries

- Our selector tool helps you to find the most relevant journal

- We provide round the clock customer support

- Convenient online submission

- Thorough peer review

- Inclusion in PubMed and all major indexing services

- Maximum visibility for your research

Submit your manuscript at www.biomedcentral.com/submit 